\title{
0 resgate de fronteiras e a emergência de movimentos nacionalistas na Europa
}

\section{Rodolfo Pereira das Chagas}

\section{Introdução}

Sempre que se analisam os processos de integração regional em todo o mundo, a União Europeia nos é apresentada como exemplo a ser seguido, já que se estruturou a partir de valores democráticos e de respeito às identidades de todos os povos pertencentes ao bloco. Não obstante, nas últimas décadas do século XX e início do século XXI, ao mesmo tempo em que se incrementava o processo de globalização em todo o mundo, o projeto da União Europeia passou a esbarrar em antigas reivindicações autonomistas e independentistas, a partir da emergência de movimentos nacionalistas estruturados sobre bases étnico-culturais e/ou cívico políticas. O desmembramento nacional ou a intensificação dos mecanismos de descentralização passaram a ser vistos como soluções para reivindicações de identidades.

Apesar do esforço europeu em estabelecer uma união econômica e monetária entre os paísesmembros do bloco, além de criar inúmeros instrumentos de proteção das minorias, tais como a Convenção Quadro para a Proteção das Minorias Nacionais (Conselho da Europa), a Carta Europeia de Línguas Regionais ou Minoritárias, entre outros, ressurgem com vigor os movimentos nacionais de defesa da identidade social e cultural de diferentes povos e nações. Sabe-se que a construção europeia aspira superar uma Europa de etnias, ou seja, a lógica dos nacionalismos não se encaixa na lógica do projeto europeu.

Nos anos pós-Guerra Fria, estes movimentos passaram a empunhar a bandeira da autonomia territorial ou do independentismo, fundados nas identidades culturais históricas e em seus passados gloriosos. Aqui se enquadram vários movimentos que perduram até hoje, tais como País Basco, Padânia, Córsega entre outros.

A Europa vem sendo palco de inúmeros movimentos nacionalistas que tendem a causar a redefinição de suas fronteiras políticas. Casos como Catalunha (na Espanha), Escócia (no Reino Unido), Flandres (na Bélgica) são alguns dos exemplos que denotam o resgate das fronteiras para o surgimento de possíveis novos Estados no velho continente, em função destes movimentos nacionalistas ${ }^{1}$.

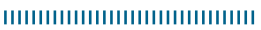

1 Importante ressaltar que nem todo movimento nacionalista é separatista. Grande parte deles luta por mais autonomia e não por independência. Ex.: Córsega e Bretanha (na França), Andaluzia (na Espanha), entre outros.

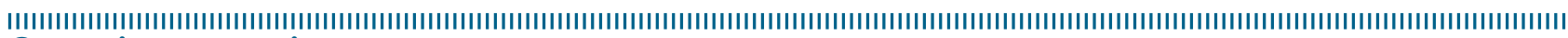
Como citar este artigo:

CHAGAS, Rodolfo Pereira das. "O resgate de fronteiras e a emergência de movimentos nacionalistas na Europa”. In: RÜCKERT, A. A.; SILVA, A. C. P. da; SILVA, G. de V. (Orgs.). Geografia Política, Geopolítica e Gestão do Território: integração sul-americana e regiões periféricas. Porto Alegre: Editora Letra1, 2018, p. 259-270 
Historicamente, a Europa foi construída a base de remendos. O Congresso de Viena ${ }^{2}$, a constante mudança de fronteiras estatais e os deslocamentos populacionais que se realizaram durante todo o século XX deixaram evidências do problema das minorias e potencializaram o desenvolvimento de movimentos nacionalistas. A Europa é um continente repleto de muitas nações e poucos Estados. A formação dos atuais Estadosnação deixou pelo caminho muitos movimentos regionalistas que não conseguiram desassociar seu caminho de outros povos ali presentes. A partir disso, a questão das secessões se torna um tema a ser enfrentado pelo continente e, mais fortemente, dentro dos limites da União Europeia.

Povos e nações sem Estado não têm reconhecimento algum e não são consultados sobre nenhuma decisão a respeito da União Europeia, fato que fratura a base democrática do bloco, além de sinalizar uma difícil convivência futura entre os povos europeus. Segundo Guibernau (1997), minorias nacionais com uma consciência nacionalista ressentem-se dos vários modos pelos quais suas instituições políticas se perderam no passado, enquanto outras estão simplesmente insatisfeitas sobre a maneira como o Estado trata dos interesses delas. Isso explica a atual ascensão do nacionalismo em nações sem Estado no continente europeu.

\section{O que veio primeiro: a nação ou o nacionalismo?}

Uma longa discussão na literatura sobre o conceito de nacionalismo opõe argumentos que, por um lado, afirmam que ele é a continuidade de uma etnicidade antiga, e por outro, asseguram que o nacionalismo é essencialmente moderno. De um lado estão os etnossimbolistas, os perenialistas e o

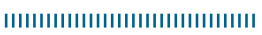

20 Congresso de Viena foi uma conferência entre embaixadores das grandes potências europeias (Áustria, Prússia, Rússia e Reino Unido) que aconteceu em Viena, entre 1814 e 1815, cujo objetivo era o de reorganizar as fronteiras europeias após a derrota da França napoleônica na Batalha das Nações, em 1813. Além disso, os países vencedores sentiram a necessidade de selar um tratado para restabelecer a paz e a estabilidade política na Europa. primordialistas e de outro, estão os modernistas.

Para os perenialistas, as nações sempre existiram em todos os períodos da história e "muitas nações existiram desde tempos imemoriais". (SMITH, 2001, p. 77). Esta corrente sustenta que os vínculos sobre os quais se alicerçam as nações são permanentes no tempo; por conseguinte, as nações não são elementos exclusivos da modernidade.

Os primordialistas entendem que as nações são primordiais, fundamentam seus discursos em uma perspectiva naturalista, entendendo que as nações existem na ordem natural, às vezes vistas como um desígnio de Deus. As nações são unidades naturais da história da humanidade, e, se algumas delas ainda não lograram manifestarse, isso advém de injustiças históricas e que os movimentos nacionalistas tencionam consertar.

O paradigma etnossimbólico valoriza os elementos subjetivos "da persistência das etnias, da formação das nações e do impacto do nacionalismo". (SMITH, 2011, p.90). Estes elementos subjetivos referem-se à memória, aos sentimentos, aos mitos e aos símbolos; já os elementos objetivos dizem respeito à língua, à religião, ao território etc. Para o autor, mais importante do que a nacionalidade é a etnicidade, isto é, o pertencimento e identificação de um indivíduo com determinado grupo étnico; daí deriva a formação das nações.

À vista da apresentação destas correntes, pode-se depreender que há uma convergência de elementos presentes entre o perenialismo, o primordialismo e o etnossimbolismo. Elas sustentam que as nações têm sua origem em grupos étnico-culturais; como estas comunidades étnicas e culturais existem desde muito tempo, infere-se que o sentimento de pertencimento a uma nação, ou seja, a nacionalidade, não é um produto da modernidade. Cada povo cria sua comunidade nacional à medida que se reiteram valores como língua, religião, símbolos, mitos, entre outros, vinculados a um território determinado, que promovem, deste modo, a formação de uma identidade nacional.

Por outro lado, há um rol de teorias produzidas pelos modernistas, que afirmam que o nacionalismo é um fenômeno que se iniciou no 
fim do século XVIII; ainda assim há divergências nas interpretações propostas por alguns desses autores. Ernest Gellner (1993) vê o nacionalismo enraizado na industrialização e surgimento de uma sociedade industrial; Eric Hobsbawn (2013) o relaciona com a invenção de uma ideologia para legitimar Estados dentro das relações econômicas capitalistas; Benedict Anderson (2008) o associa ao desenvolvimento de novas retóricas para a identidade de um grupo (desenvolvimento das comunicações, imprensa, símbolos etc.).

Para os modernistas, a nação não é um ente espiritual, presente desde tempos remotos no caráter dos povos, mas sim, um produto da modernidade, uma vez que grupos que partilhavam uma cultura comum e que não tinham consciência nacional, passaram a tê-la, à medida que o discurso nacional foi o principal instrumento para a consolidação dos Estados nacionais. Em outras palavras: língua, religião, símbolos, os quais tinham caráter essencialmente cultural antes da modernidade, passaram a ter uma caraterística eminentemente política.

Já o nacionalismo, como fenômeno desencadeado na Europa pós-Revolução Francesa e/ou Romantismo alemão (segundo a corrente modernista), estava atrelado às transformações verificadas na estrutura das sociedades modernas. A imposição de fronteiras, derivada da criação de Estados, fez com que os indivíduos se compartimentassem em grupos, ajustandose a tipos particulares de sociedade. Isto se dava a partir do poder do Estado, que através do uso de mecanismos de controle (sistema educacional, legislação, políticas públicas, meios de comunicação, entre outros), sobrepujava identidades coletivas às de um grupo específico.

A linha adotada neste artigo é a de que as nações, como comunidades que partilhavam valores (etno)culturais, de fato existiam antes da chamada modernidade; todavia, foi a partir da delimitação de fronteiras com o Tratado de Westfália - e consequente surgimento dos Estados-nação -, e com as ideias desenvolvidas pela Revolução Francesa, tais como igualdade, liberdade, fraternidade, solidariedade e soberania nacional, que a nação passou a ter uma dimensão mais política e abriu-se caminho para o advento do nacionalismo.

Entende-se o nacionalismo como um fenômeno cultural e politicamente construído, alicerçado em inúmeros vetores, tais como etnia, território, idioma, religião, formas de governo, identidades oprimidas e, sobretudo, pelo interesse de determinado grupo que por alguma circunstância se sente subjugado.

O conceito de nacionalismo se associa à ideia de autonomia, à aspiração por parte dos membros de uma comunidade nacional para viver de acordo com leis próprias, livres de qualquer interferência externa, à unidade territorial, à identidade, entendida como a principal idiossincrasia daquele povo, ao sentimento de pertença, visto como apego pelos membros da comunidade a um território, e à continuidade, principalmente das ligações aos antepassados, numa ideia de perene sucessão através, essencialmente, da manutenção das memórias e das tradições.

Na era da Revolução Francesa surgem duas visões clássicas de nação. A visão política e a visão étnica de nação. A primeira sustenta que a nação se constitui com cidadãos e, portanto, cada qual pode escolher se quer ou não ser cidadão de uma nação. Já a segunda assegura que a nação é uma realidade natural. Daí derivam as expressões nacionalismo cívico-político e nacionalismo étnico-cultural.

O nacionalismo cívico baseia-se na concepção política de cidadania, independentemente de raça, religião, língua, etnia, local de origem. A condição nacional se assenta em uma cidadania comum e a nação é entendida como uma livre associação política dos cidadãos. Elevam-se elementos como voluntariedade e comportamento, além de alguns anos de permanência em um país, o aprendizado do idioma etc. Esta dimensão cívica nasce na França, foi conceituada pelo Iluminismo, concretizada na Revolução Francesa e muitos autores a associam aos nacionalismos da Europa Ocidental. Já o nacionalismo étnico é mais excludente e tem mais tendências à xenofobia, ao etnocentrismo e ao autoritarismo. A condição nacional tem como pilar o caráter étnico comum, a expressão 
de um sentimento identitário, o reflexo de uma ordem natural. É dada importância a elementos associados a aspectos naturais, tais como o sangue.

Alain Dieckhoff (2000, p.58) assegura que esta divisão entre dois tipos de nacionalismos surgiu sob as circunstâncias da contenda acerca da possessão da região de Alsácia-Lorena, nos anos 1870. "Aos historiadores alemães que justificavam a incorporação dos alsacianos no Reich por motivo de sua cultura alemã, os seus homólogos franceses ripostaram defendendo o direito dos alsacianos a permanecerem franceses se fosse essa a sua opção política".

Atualmente, nota-se que há uma interrelação entre os dois tipos de nacionalismos, principalmente na Europa. Países que têm longa experiência democrática, calcados em uma nação mais voluntarista e cidadã, tais como França e Bélgica, convivem com a ascensão de fortes movimentos ligados a aspectos étnicos, a lideranças políticas que defendem preservação cultural, barreiras à imigração - ações bastante etnocêntricas. A subjugação de minorias étnicas diminui a vontade de participação cívica destas minorias, recrudescendo o desenvolvimento de movimentos nacionalistas e irredentistas.

Por fim, vale ressaltar que os nacionalismos podem ter tendências centrípetas ou centrífugas. $O$ nacionalismo centrípeto busca preservar unida ou vir a unir, na mesma entidade política (geralmente os Estados), uma ou várias identidades nacionais, no quadro de maior integração possível. Afirma Romão (2014, p. 66) que

... a opção pelo termo centrípeto prende-se com a evolução dos sistemas políticos democráticos. No contexto dos Estados autonômicos, a expressão “centralizador" tende a perder força. Nestes casos, a descentralização política é perfeitamente compatível com a existência de uma identidade nacional, que, a partir do governo central, procure manter a supremacia sobre outras identidades presentes no mesmo território.

Já o nacionalismo centrífugo procura se distanciar deste projeto de integração, promovido pelos Estados, em que determinada nação está inserida. Para Romão (ibidem), o seu objetivo final pode ser a independência de uma entidade política ou a obtenção de maior autonomia, no quadro de um Estado autonômico ou federal".

Enquanto no século XIX, o nacionalismo teve características essencialmente centrípetas e integradoras, no século XX passamos a assistir a um renascimento das tendências centrífugas que afetaram importantes países europeus, tais como: França (o nacionalismo bretão, corso e occitano), Reino Unido (reivindicações escocesas, galesas e irlandesas), Espanha (a questão da Catalunha, do País Basco e da Galícia), Bélgica (Flandres) entre outros.

\section{A relação entre fronteira e nacionalismo na Europa}

A expressão fronteira pode ser utilizada com inúmeras acepções, entre elas, o limite entre estados nacionais, ou metaforicamente, como diferenças socioeconômicas, obstáculos a determinados assuntos etc. Há ainda um outro aspecto a ser tratado com relação às fronteiras que aponta que elas também são zonas de interação sociocultural e econômica. Segundo Costa (2008, p.280), "as ideias de fronteira-zona e de fronteiralimite são as mais consagradas nas análises que envolvem este tema".

A origem do conceito, o qual deriva do latim "fronteira ou frontaria", indicava "a parte do território situado in fronte, ou seja, nas margens, consignando, portanto, uma qualidade e não uma entidade". (MARTIN, 1993, p. 78). Posteriormente, adquire o significado de divisão entre Estadosnacionais, sendo associada à política e ao poder.

Foucher (2009) declara que desde 1991, mais de 26 mil quilômetros de novas fronteiras foram instituídos e outros 24 mil foram objeto de acordos de delimitação e demarcação, além da construção de muros, cercas e inúmeras barreiras. Houve também a extinção de alguns limites, como foram os casos de Alemanha, Iêmen e Vietnã. Afirma, ainda, que o mundo contemporâneo está estruturado por 248 mil quilômetros de fronteiras políticas terrestres e 332 fronteiras entre Estados. Para ele, "criar uma fronteira visa sempre solucionar um problema, incontestável ou não, sem nunca saber 
o que acontecerá em seguida". (2009, p. 11). Ainda segundo o autor:

As fronteiras são descontinuidades territoriais, com a função de demarcação política. Nesse sentido, trata-se de instituições estabelecidas por decisões políticas, projetadas ou impostas, e administradas por textos jurídicos: as leis de um estado soberano em seu interior, o direito internacional público como lei comum da coexistência dos estados, mesmo quando estes se desfazem, porque os tratados territoriais são os únicos pelos quais a sucessão de estado é automática. (FOUCHER, 2009, p. 22).

A raiz da definição ligada à geografia política tem sua origem em Ratzel, no século XIX. Para ele, "as fronteiras são o órgão periférico do Estado, o suporte e a fortificação de se crescimento, e participam de todas as transformações do organismo do estado". (RATZEL apud MORAES, 1990, p. 184)

O autor prussiano assegura que frequentemente as fronteiras políticas são ao mesmo tempo linhas de evidente separação entre as características nacionais, entretanto, em alguns casos, eventuais diferenças de religião e língua fazem com que povos que vivem juntos apresentem características muito diversas. Neste aspecto, evidencia-se que desde muito tempo os movimentos nacionalistas têm, como principal mote, o fato de povos que se constituem por diferentes elementos étnicoculturais viverem juntos num mesmo território e outros, que têm naturezas semelhantes, estão separados por fronteiras criadas artificialmente. Afirma o autor:

Nenhum dos povos de hoje apresenta um tipo étnico único. Cada um deles é formado pela reunião de duas e frequentemente até de mais frações dos diversos povos que pela turbulenta sucessão histórica dos três últimos milênios não tiveram meios de se fundir entre si completamente. (RATZEL apud MORAES, 1990, p. 65).

Para Ratzel, a fronteira era o invólucro do Estado dentro do qual ele se desenvolve; ela retratava apenas um momento de desenvolvimento do Estado, podendo ser alterada. Considerava o mar como a mais perfeita das fronteiras.

Outro importante autor que discute o conceito de fronteira é Claude Raffestin. O geógrafo francês sustenta que as noções de limites e fronteiras sempre existiram e seus significados mudaram no decurso da História. Para ele, enquanto o limite é um sistema de sinais usado por uma coletividade para demarcar um território, já as fronteiras são um tipo de limite e que ganharam mais expressivas quando os Estados-nação as tomaram como principal sinal que denotava controle territorial. Além disso, ela "é manipulada como um instrumento para comunicar uma ideologia [...] e só é de fato estabelecida quando a demarcação se processa". (RAFFESTIN, 1993 p. 166)

Pode-se relacionar a questão do nacionalismo à conceituação de fronteira proposta por Raffestin, quando ele assevera que "as funções da fronteira entre os blocos surgidos de ideologias diferentes adquirem uma forma extrema". (ibid, p.167) Entre as funções apontadas pelo autor (legal, de controle, fiscal, ideológica e militar ${ }^{3}$ ), a legal é a que mais se associa à exacerbação de movimentos nacionalistas, pois ela "delimita uma área interna da qual prevalece um conjunto de instituições jurídicas e normas que regulamentam a existência e as atividades de uma sociedade política". (ibid, p.168) Verifica-se, neste caso, as situações em que os Estados criam sistemas de educação, de comunicação, leis comuns, feriados nacionais, que emanam da maioria nacional, com o intuito de integrar ou subjugar as minorias nacionais. Por conseguinte, surgem os nacionalismos e o anseio de mais autonomia e/ou independência por parte destas minorias. Quando este fenômeno acontece (épocas excepcionais, nas palavras do autor), podese imaginar que haja um fortalecimento " $d a$ função de controle no próprio interior do país, ao longo das fronteiras internas". (Ibidem, p.168)

A. E. Moodie, em seu livro "Geografia e Política" (1965), propõe também um estudo acerca dos conceitos de fronteira e limite. Para ele, as linhas

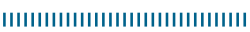

3 Segundo Raffestin, a função de controle tem por dever inspecionar a circulação dos homens, dos bens e da informação de uma maneira geral. A função fiscal representa o papel de instrumento de política econômica. A função ideológica esconde os conflitos armados potenciais. Por fim, a militar é ambígua, pois só pode ser assumida num contexto estratégico convencional - os armamentos sofisticados a esvaziaram, em grande parte, de todo o significado. 
divisórias se fazem imprescindíveis, pois o controle estatal tem se expandido até ferir a soberania dos outros Estados. Afirma que "as fronteiras são zonas ou faixas de território que encerram área, grande ou pequena, e estão sujeitas à mudança contínua sempre que a ação humana lhes altera a natureza e serventia". (MOODIE, 1965: 83) São também, segundo ele, regiões de discórdia entre países vizinhos; por conseguinte, tornam-se elementos que abalam as relações interestatais.

O geógrafo americano sustenta que a natureza do Estado moderno requer o estabelecimento de limites bem definidos para sua área de soberania e organização. Sem eles, "o presente sistema de Estados ficaria reduzido ao caos, pois seria impossivel saber onde terminaria a soberania de um Estado e onde começaria a do outro". (ibidem, p. 83)

$\mathrm{O}$ autor remete-se, indiretamente, aos movimentos nacionalistas da Europa quando faz uma análise histórica da região de Alsácia-Lorena:

Os nomes dos lugares e a língua falada pela maioria dos alsacianos revelam íntimas ligações com a Alemanha, reforçadas pelos laços econômicos com este país através das estradas de rodagem do Reno, do vale do mesmo nome, porém suas afinidades espirituais são com a civilização francesa. Linguística, econômica e culturalmente é, portanto, uma zona marginal sujeita às influências do Leste e Oeste e, necessariamente, seu povo acha-se dividido por compromissos de fidelidade que se entrechocam. Raramente era consultada a vontade dos habitantes quando se tomavam resoluções para a fixação do seu território. (MOODIE, 1965, p. 90).

Este exemplo aclara a situação de possibilidade de convulsão social ocasionada pela tentativa de um Estado-nação em impor sobre um povo elementos político-culturais, com o objetivo de convencer estas populações fronteiriças a incorporarem aspectos que são vitais à manutenção de sua integridade territorial. Para o êxito destas ações, elevam-se discursos fundamentados em direitos históricos, terra irredenta, passados gloriosos etc., que ao fim e ao cabo, fortalecem a ideia de uma identidade e uma consciência nacionais que requerem a anulação ou subjugação dos elementos culturais ligados a outra nação (neste caso, a França tentava eliminar o conteúdo político- cultural alemão que ainda perdurava na região de Alsácia-Lorena).

Por fim, Moodie assevera que não há duas regiões fronteiriças idênticas; " a única semelhança é que elas vêm servindo e podem tornar-se zonas de conflito, de tensão e de disputa entre os estados interessados". (1965, p.91).

Após a análise das acepções de fronteira propostas por Ratzel, Raffestin e Moodie, infere-se que a fronteira política vê nos limites jurídicos do Estado o maior potencial para sua efetivação, seja no aspecto de defesa militar da nação (quando se desenvolvem estratégias para proteção do território), seja na preservação de determinada cultura - quando há o fortalecimento de identidades nacionais com intuito de manter a integridade político-cultural sustentada pela Estado-nação.

Durante a Guerra Fria, em função dos traços que demonstravam que as fronteiras políticas e ideológicas estavam estabelecidas e consolidavamse os movimentos de autodeterminação dos povos, algumas teorias, principalmente as que estão na base das Relações Internacionais, analisaram a questão das fronteiras.

A escola realista, cujas principais referências são Morgenthau, Waltz, Bull e Aron, sustenta que o Estado é o ator central das Relações Internacionais; este Estado tem duas funções essenciais: garantir a paz dentro de suas fronteiras e garantir a sobrevivência de seu povo, defendendo os interesses nacionais. Não havia grande preocupação com o que acontecia internamente, dentro do Estados. Além disso, perder a soberania significava diminuir poder e, em uma situação mais extrema, deixar de existir como unidade autônoma. Para Morgenthau (2003, p. 578),

A soberania pressupõe a suprema autoridade legal de uma nação para aprovas leis e fazê-las cumprir dentro de um determinado território e, como consequência, a independência em relação à autoridade de qualquer nação e igualdade com a mesma nos termos do direito internacional.

Seguindo-se o raciocínio sobre a perda de soberania, Raymond Aron (2002, p. 254) afirma 
que: "A violação da linha que separa o território das unidades políticas é um casus belli ${ }^{4}$ por excelência e prova de agressão". Para Scherma (2012, p. 113), "esse tipo de acontecimento é muito mais provável de ocorrer na região fronteiriça do que na capital do país. As fronteiras muitas vezes são constituídas por obstáculos naturais e são regiões onde a vigilância em geral é menor".

Conforme expresso anteriormente, o ponto do Estado é o seu poder soberano; essa soberania é exercida por um governo central, que agrega a si maiores poderes ao longo do tempo e que conta com a fidelidade de seus habitantes. Em Estados plurinacionais, esse aumento de poderes do Estado no decurso do tempo pode causar um efeito secundário: a insatisfação das minorias étnicas e nacionais, que acabam por promover uma organização interna que pode destoar dos mecanismos administrativos propostos pelo Estado. Uma alternativa para que não haja o colapso no mecanismo estatal, afirma Moodie (1965, p. 63):

Nos grandes estados federativos do mundo, por exemplo, os Estados Unidos, o Canadá e a Austrália, os estados ou províncias administrativos contam com considerável autonomia, porém nos estados menores e mais compactos, tais como a maioria deles na Europa, as divisões internas, condados, départements, etc., não são autônomos, porém possuem considerável autoridade administrativa no âmbito da estrutura geral. ${ }^{5}$

Pode-se depreender que a partir da perspectiva estadocêntrica elevada pelos realistas, as fronteiras tornam-se componentes importantes, uma vez que desempenham rol de uma região delicada, vulnerável para o Estado. Para os realistas, ainda que houvesse uma particularidade regional, não se pode empregar uma política para as fronteiras que entrasse em desacordo com os interesses

||IIIIIIIIIIIIIIIIIIIIIIIIIIIIIIIII

4 A expressão latina casus belli designa um fato grave de ofensa a um Estado, sendo a circunstância para o estado ofendido declarar guerra ao estado ofensor.

5 Importante ressaltar que alguns países europeus caminharam em direção à maior autonomia de suas províncias ou regiões internas. Um exemplo é a Espanha, que desde 1978, criou uma nova Constituição que dividia o país em dezessete comunidades autônomas. nacionais. Estas áreas devem ser vigiadas, pois como há um alto grau de circulação de pessoas e bens (desejáveis ou não), elas de fato tornamse mais suscetíveis à ação de atores que podem comprometer a soberania daquele Estado.

A partir dos anos 70, ganha força o paradigma (neo)liberal nas Relações Internacionais. Segundo Castro, "o liberalismo não desconsidera a importância do Leviatã, porém, enxerga outras forças pulverizadas juridicamente guiadas no interior e no exterior dos Estados que possuem papel legitimamente nas Relações Internacionais" (2012, p. 338). Além disso, existe um pensamento otimista sobre a natureza humana, há confiança no progresso humano, a divisão de responsabilidades comuns em benefício da paz, da justiça e da cooperação, assim como exalta-se a força normativa das instituições multilaterais, dos regimes internacionais e das regras pactuadas entre os povos.

Nesta mesma década, ganham força as teorias globalistas, principalmente capitaneadas por Keohane e Nye ${ }^{6}$. Os autores norte-americanos escreveram a teoria da interdependência complexa, que assegurava que o mundo "não era mais moldado pela exclusão de interesses, mas racionalmente ordenado pela cooperação econômica de ganhos compartilhados, onde o uso da força militar seria mormente desnecessário, prevalecendo a resolução pacífica de conflitos". (ALBUQUERQUE, 2012, p. 213). Nesta abordagem, "as fronteirasseparação se transformam em fronteiras-cooperação, e as linhas rígidas dos limites fronteiriços geopolíticos em zonas flexíveis de cooperação econômica em redes". (ibidem, 213)

Keohane e Nye ponderam que o fenômeno da interdependência ocorre quando um país toma uma decisão e isto afeta, em maior ou menor grau, outros países. Por conseguinte, "no mundo interdependente, a união de forças para aumentar poder e competir em escala global também passa a ser um fenômeno recorrente". (SCHERMA, 2012 p. 116) A implantação de regimes internacionais e

IIIIIIIIIIIIIIIIIIIIIIIIIIIIIIIIIIII

6 Robert Keohane e Joseph Nye publicaram em 1977 a obra "Relações Transnacionais e Poder Mundial e Poder e Interdependência" 
blocos econômicos surge como uma alternativa para este contexto de interdependência.

$\mathrm{Na}$ década de 90, Castells, ao analisar a União Europeia, argumenta a favor do chamado "estado em rede", que é caracterizado "pelo compartilhamento de autoridade em uma rede". (2012, p. 407). Assegura o autor:

O Estado em rede não significa a inexistência de relações políticas assimétricas e desiguais entre instituições e instâncias governamentais. Não obstante, os vários nós do Estado em rede europeu são interdependentes, de forma que nenhum nó, nem o mais poderoso, pode ignorar os outros, nem mesmo os menores, no processo decisório. (CASTELLS, 2012, p. 407).

A partir das proposições acima, percebe-se que entre os (neo)liberais fala-se em ampliação do poder do Estado em soberanias compartilhadas e que o conceito clássico de fronteira política, desde uma perspectiva ratzeliana, passou a coexistir com novas concepções que se remetem "a uma economia global transfronteiriça." (ALBUQUERQUE, 2012, p.214)

Seguindo-se nesta análise do continente europeu, ao longo do tempo, e mais especificamente nas últimas três décadas, as fronteiras geográficas da Europa experimentaram modificações significativas, por exemplo: a unificação da Alemanha, a separação da Tchecoslováquia, o (res) surgimento de inúmeros países europeus com a desintegração da União Soviética e da Iugoslávia, o processo de anexação da Crimeia à Rússia. Todos estes casos ilustram o vultoso remodelamento que o velho continente vem enfrentando desde o fim da Guerra Fria. Neste sentido,

Os anos 1990 pareciam afirmar um processo de banalização das fronteiras políticas, oriundo tanto da multiplicação exacerbada do número de Estados-Nação quanto da abertura econômica. No caso soviético e iugoslavo isto ocorreu simultaneamente, redundando em cerca de duas dezenas de novos estados formalmente soberanos e geopoliticamente débeis. (ALBUQUERQUE, 2012, p. 212).

Em contrapartida surgiu uma "nova fronteira" que abarca a União Europeia. Apesar de a Europa ser entendida como uma realidade que se estende para além dos limites daquele bloco regional, em muitos casos, ambos os nomes, Europa e União Europeia, passaram a ser usados como sinônimos. Vale ressaltar que quando se fala na criação de uma identidade europeia, nos referimos ao processo encampado pela União Europeia. Esta situação lembra "o método de consolidação territorial do século XVIII: recuar as fronteiras para estabelecer os limites". (FOUCHER, 2009, p. 19).

A abertura das fronteiras europeias e o deslocamento das competências a múltiplos níveis “quebrou a velha fórmula do Estado-nação no qual as funções, instituições e sistemas de representação coincidiam dentro das mesmas fronteiras, com o qual se realçava a política interior e reforçava a integração estatal". (KEATING, 2012, p. 91, tradução nossa) ${ }^{7}$.

Em toda a Europa, o processo de unificação provocou o aparecimento de movimentos de reafirmação territorial e a busca de novos instrumentos para atuar neste contexto de integração. Surgiram movimentos para criar a Europa das Regiões, aspirando contornar os antigos Estados e buscar novas fórmulas para conseguir autonomia. Com relação às reinvindicações independentistas que emanam dos movimentos nacionalistas, assevera Keating (ibid, p.92),

Os movimentos nacionalistas passaram de um grande ceticismo em torno à integração europeia a um apoio generalizado, pois, para alguns, a Europa proporciona a oportunidade da independência com um custo mais baixo e com a segurança que proporciona um sistema de apoio externo. ${ }^{8}$

Os Estados-nação europeus, em sua maioria, não se constituem por uma única nação, cujos limites coincidem com os do Estado. "As minorias étnicas e nacionais são elementos que compõem a paisagem sociocultural europeia". (GUIBERNAU,

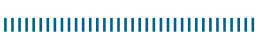

$7 \mathrm{La}$ apertura de fronteras ha quebrado la vieja fórmula del Estado-nación en el que las funciones, instituciones y sistemas de representación coincidían dentro de las mismas fronteras, con lo que realzaba la política interior y se reforzaba la integración estatal.

8 Los movimientos nacionalistas han pasado de un gran escepticismo en torno a la integración europea a un apoyo generalizado. Para algunos, Europa proporciona la oportunidad de la independencia con un coste más bajo y con la seguridad que proporciona un sistema de apoyo externo. 
2009, p. 157, tradução nossa). ${ }^{9}$ Com relação à congruência dos limites entre Estado e nação, Guibernau (1997) defende que a partir da coexistência ou não destes dois elementos, teremos a classificação de dois tipos de Estados: os legítimos e ilegítimos.

Os Estados legítimos são aqueles em que há concomitância entre os limites do Estado e da nação. Neste caso, "o nacionalismo é favorecido pelo Estado como um meio de homogeneizar sua população e aumentar seu grau de coesão". (GUIBERNAU, 1997, p. 69). Portanto, a nação é entendida como uma comunidade que comparte alguns dos seguintes elementos: cultura, território, língua, religião, etc. Desta forma, surge uma situação de pertencimento àquela nação. Neste processo,

(...) o nacionalismo usa elementos pré-existentes da cultura da nação, mas não apenas revive tradições, como também as inventa e transforma. O nacionalismo, neste caso, impregna a vida diária do estado nacional e só aparece em primeiro plano em situações específicas, quando a integridade do estado nacional está em perigo ou há a necessidade de defender certos interesses, por exemplo, a reação do povo britânico à Guerra das Malvinas. (GUIBERNAU, 1997, p. 69).

Em geral, estes chamados "Estados legítimos" ficam restritos a países que não sofrem pressões étnicas em suas fronteiras, como é o caso do Japão.

Já os Estados ilegítimos referem-se àqueles que incluem em seus territórios distintas nações ou partes de outras nações. Não há congruência entre os limites das nações e as fronteiras dos Estados. Em geral, uma nação se sobrepõe às demais nestas situações, ou seja, o Estado não beneficia de maneira equânime todas as nações que a ele estão subordinadas. Isto gera problemas, pois

Enquanto todos os indivíduos que vivem no território do estado são considerados cidadãos, que têm os mesmos direitos e deveres, mostrando o mesmo passaporte e pagando os mesmos impostos, na verdade existe uma espécie de discriminação que provém do fato de o estado tentar incutir uma cultura comum, uma série de símbolos e valores, e perseguir um programa de homogeneização

| |||||||||||||||||||||||||||||||||||||

9 Las minorías étnicas y nacionales son elementos que componen el paisaje sociocultural europeo. entre os cidadãos. Isso acontece porque o estado, para defender sua legitimidade, procura criar uma nação. (Ibidem, p. 70)

Nos chamados Estados ilegítimos, há dois desdobramentos que podem ocorrer dependendo da maneira como este Estado lida com as minorias nacionais aí presentes. Vale ressaltar que minoria nacional deve ser entendida como um povo ou uma nação que está circunscrito a um determinado território de um Estado, com características definidas e que, na maioria dos casos, luta por mais autonomia ou independência. Nos casos de autonomia, há o interesse em maior representação política, um sistema jurídico próprio etc.

O primeiro efeito é que o Estado obtém êxito ao assimilar as diferentes nações existentes em seu território. Neste caso, há uma integração destas minorias à chamada cultura principal. Alguns grupos etnoculturais, que englobam as minorias nacionais e as minorias étnicas ${ }^{\mathbf{1 0}}$, aceitam esta chamada integração; em alguns países, como França e Alemanha, o resultado de programas de construção nacional, encampados pelo Estado, foi o da irradiação de uma cultura comum por todo o território.

Já em outros casos, as minorias se rebelam contra esta integração, pois fazem com que suas línguas e instituições coexistam ao lado dos elementos da cultura dominante. Ex. Bélgica e Espanha. Nesta circunstância - de não ajustamento à cultura majoritária - estas minorias lutam para conseguir os direitos necessários para conservar sua própria cultura, criando suas próprias instituições econômicas, políticas e educacionais, fomentando sua própria língua. Evidencia-se, assim, a gana destes grupos em se apartar dos valores compartilhados pela maioria nacional, para que, desta forma, consigam manter suas práticas culturais que os singularizam e lhes conferem uma identidade nacional particular.

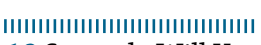

10 Segundo Will Kymlicka (2004), enquanto as minorias nacionais são sociedades distintas e potencialmente autogovernadas incorporadas a um estado mais amplo, as minorias étnicas estão formadas por indivíduos que abandonaram sua comunidade nacional para se incorporar a outra sociedade. Há ainda as minorias emigradas que se referem ao coletivo de pessoas que abandonaram seu país de origem e aspiram a uma melhora de sua situação no estado receptor. 
Muitos grupos minoritários resistem à integração e pleiteiam sua autonomia e/ou independência porque o processo de construção nacional privilegia os membros da cultura majoritária:

Se uma sociedade moderna possui uma língua oficial, advogada pelo estado, uma língua e uma cultura perfeitamente definidas as quais se concretizam nas funções estatais e jurídicas, não há dúvida de que qualquer indivíduo que disponha dela como língua materna possui uma grande vantagem. Os falantes de outras línguas se encontram em franca desvantagem. (KYMLICKA, 2004, p. 59, tradução nossa). ${ }^{11}$

Já o segundo efeito possível ocorre quando o Estado não incorpora as minorias nacionais; desta forma, os indivíduos que se encontram nesta situação sentem-se estrangeiros naquele Estado. Por conseguinte, pode ocorrer um fortalecimento de movimentos nacionalistas que emanam destas minorias e um enfraquecimento da lealdade ao Estado, ou seja, um decrescimento do patriotismo. Pode-se citar, como exemplo, a Catalunha que, a despeito da autonomia dada pelo governo espanhol a esta região, a lealdade ao Estado, por parte de uma fatia dos catalães, diminuiu consideravelmente nos últimos anos, processo acelerado por questões econômicas.

A imposição de uma língua às minorias nacionais ameaça a existência de sua cultura, que é, em vários aspectos, diferente da maioria, pois "sua língua e sua narrativa histórica estão plenamente imbricadas em um amplo conjunto de práticas e instituições sociais, que são postas em perigo por causa dos esforços da maioria dominante em difundir a sua cultura societal comum". (KYMLICKA, 2004, p. 61 , tradução nossa) ${ }^{12}$.

||IIIIIIIIIIIIIIIIIIIIIIIIIIIIIIIII

$11 \mathrm{Si}$ una sociedad moderna posee una lengua oficial, en el sentido más amplio de la expresión, es decir, esponsorizada por el Estado, una lengua y una cultura perfectamente definidas - e inculcadas-, las cuales se concretan en las funciones estatales y en el tráfico jurídico mercantil, no hay de duda que cualquiera que disponga de ella como lengua materna posee una gran ventaja. Los hablantes de otras lenguas se encuentran en franca desventaja.

$12 \mathrm{Su}$ lengua y su narrativa histórica están plenamente imbricadas en un amplio conjunto de prácticas e instituciones sociales, abarcadoras de todos los aspectos de la vida social, que serán puestas en franco peligro a causa de los esfuerzos de la mayoría dominante por difundir su cultura societal común.
Neste sentido, Kedourie (2015, p. 114) assegura que uma das provas pelas quais se reconhece a existência de uma nação é a do idioma. Portanto, os elementos que compartilham esta língua deveriam constituir um Estado. Entretanto, o que se verifica é que vários destes grupos estão separados por fronteiras. Neste caso, a autor sugere que estas fronteiras são arbitrárias, artificiais e injustas. Vale ressaltar, que a afirmação de Kedourie difere da proposta por Raffestin, quando o último afirma que "todo sistema de limites é convencional, mas desde o momento em que foi pensado, colocado no lugar e que funcione, ele não é mais arbitrário, pois facilita o enquadramento de um projeto social, aquele mesmo de uma sociedade". (RAFFESTIN, 1993, p. 65).

Uma vez que há a maior incidência de Estados ilegítimos, a diversidade interna passa a ser a regra. As nações ou partes de nações incluídas em um mesmo Estado adotam distintos graus de consciência nacional. Além disso,

Assim como algumas que se definem como nações, compartilham uma identidade comum e arraigadas em memórias históricas de épocas em que desfrutaram de um status como independente - como são os casos de Escócia, Catalunha, Flandres e País Basco -, outras têm um sentido de identidade menos desenvolvido e se conformam sendo denominadas como regiões ${ }^{13}$ - entre as quais figuram Bretanha e Occitânia. (GUIBERNAU, 2009, p. 158, tradução nossa). ${ }^{14}$

Nestas situações, nota-se que os movimentos nacionalistas não tornam fáceis as relações entre grupos diferentes em áreas de limites nacionais, uma vez que fomentam uma redefinição de fronteiras e uma redistribuição de poder político para atender às demandas de uma nacionalidade em particular. Segundo Kedourie (2015, p. 180,

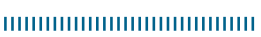

13 Segundo a autora, o termo região, tal como se emprega na União Europeia, não distingue entre uma região geográfica, uma região econômica, uma região com uma frágil cultura distintiva e uma região dotada de um forte sentimento de identidade e de cultura.

14 Así como algunas se definen como naciones, comparten una identidad común y arraigadas memorias históricas de épocas en que disfrutaron de un estatus independiente - como es el caso de Escocia, Cataluña, Flandes y el País Vasco-, otras tienen un sentido de identidad menos desarrollado y se conforman con ser denominadas regiones - entre las cuales figuran Bretaña, Occitania y Cornualles. 
tradução nossa) ${ }^{15}$ estes movimentos "tendem a desbaratar qualquer tipo de equilíbrio que se tenha podido conseguir entre diferentes grupos, recolocando questões resolvidas e renovando a luta". Para o mesmo autor, "em geral é uma condição necessária das instituições livres que as fronteiras do estado coincidam no essencial com as da nacionalidade" (ibidem, p. 194). ${ }^{16}$

A abertura de fronteiras na Europa nos últimos anos - em função da consolidação da União Europeia -, caracterizada pela depreciação de certas obrigações no que tange a algumas barreiras em relação aos traçados internacionais, "não anula $o$ feito de identidade" (FOUCHER, 2009, p.24). Ainda segundo o mesmo autor, "não há identidade sem fronteiras" (ibid, p.22). Na Europa, suprimiram-se limites internos, principalmente no que se refere à circulação de pessoas e mercadorias; entretanto, muito tem se questionado se a Europa não deve "resgatar" as fronteiras. Esta afirmação vai ao encontro das últimas atitudes tomadas por alguns países da União Europeia, quando houve um afluxo maciço de refugiados àquele local. Países como Hungria e República Checa, em 2015, colocaram barreiras físicas nas fronteiras com países vizinhos, com intuito de evitar a chegada de refugiados advindos de áreas de conflitos, tanto do Oriente Médio, quanto do Magreb africano.

À vista dos questionamentos sobre a fixação de fronteiras internas na União Europeia, há ainda a questão dos limites dentro dos próprios EstadosNação que a compõem. Além do hibridismo cultural que deriva, entre outras razões, do maior afluxo de migrantes à região e que, teoricamente afeta a integridade cultural de vários países europeus, e do maior controle da circulação de indivíduos extracomunitários, eleva-se a matéria sobre os limites internos em função da ascensão dos movimentos nacionalistas, que em alguns casos, sustentam a consolidação das chamadas fronteiras históricas, ou seja, que em algum momento da

| ||||||||||||||||||||||||||||||||||||||

15 Estos movimientos tienden a desagregar cualquier tipo de equilibrio que se haya podido conseguir entre los diferentes grupos, recolocando cuestiones ya resueltas y renovando la lucha.

16 En general es una condición necesaria de las instituciones libres que las fronteras del Estado coincidan en lo esencial con las de la nacionalidad. história existiram em função da separação e depois, agregação de povos com raízes identitárias distintas. Kedourie (2015) nomina estas fronteiras históricas como fronteiras naturais, que foram se conformando a partir, principalmente, do elemento linguístico de cada povo em questão. Afirma o autor:

Com a difusão do nacionalismo, as fronteiras naturais se transformaram nas fronteiras de uma nação determinadas por um mapa linguístico. Esta era a perspectiva de Fichte $^{17}$ : as fronteiras eram o símbolo europeu da existência de uma nação: os que falam o mesmo idioma se encontram unidos uns aos outros por uma multidão de laços indivisíveis pela mesma natureza muito antes de que comece qualquer arte humana. (KEDOURIE, 2015, p. 182, tradução nossa). ${ }^{18}$

As chamadas fronteiras naturais, nas palavras de Kedourie, que pretendem encerrar cada nação dentro de um território fixado, não asseguram automaticamente a paz internacional, nem acabam com as zonas mistas onde mais se inflamam as paixões nacionalistas. Neste sentido, corrobora Foucher (2009, p. 27), "as fronteiras são o tempo inscrito no espaço; elas permanecem testemunhas do passado ou de fronts vivos, segundo as conjecturas locais, mas sempre lugares de memória e, às vezes, de ressentimento".

\section{Considerações finais}

Os movimentos nacionalistas catalão, escocês, flamengo, basco etc. são alguns dos que eclodiram em uma Europa, que apesar dos esforços de unificação, ainda não soube lidar com a luta das minorias, com os movimentos separatistas, e ao fim e ao cabo, com a sua perda de identidade(s),

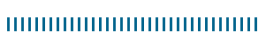

17 Nas palavras de Suzman (1999), Johann Fichte, no início do século XIX, afirmava que cada grupo possuidor de uma distinta linguagem constituía uma nação separada e que deveria ter e controlar seu próprio estado.

18 Con la difusión del nacionalismo, las fronteras naturales se convirtieron en las fronteras de una nación determinadas por un mapa lingüístico. Esta, como ha señalado, era la perspectiva de Fichte: las fronteras, mantenía, eran el símbolo europeo de la existencia de una nación; los que hablan un mismo idioma se encuentran unidos unos a otros por una multitud de lazos invisibles por la misma naturaleza mucho antes de que comience cualquier arte humano. 
dado o seu alto grau de cosmopolitismo. O que se percebe é que os atuais movimentos nacionalistas apontam para um caminho que o continente talvez não contemplasse: o de uma consciência de nação muito mais arraigado do que um sentimento europeu, além de resgatar a temática das fronteiras, fortemente elevada com as recentes questões da Crimeia (2014), do Brexit (2016) e do referendo unilateral de independência encampado pelos catalães (2017).

Nos países onde a língua e a cultura são significativamente diferentes, governos nacionais têm sido desafiados por movimentos separatistas e autonomistas. Neste sentido, esses governos têm enfrentado a contenda de manter sua coesão interna, cedendo poderes e competências administrativas às regiões nacionalistas, através de processos de descentralização. Ações como a divisão da Espanha em Comunidades Autônomas em 1978, a (re)criação do parlamento escocês em 1998, a autonomia linguística das regiões de Flandres e Valônia, na Bélgica (1962), são alguns dos exemplos que vão ao encontro deste princípio: evitar a fragmentação territorial, a partir da concessão de mais autonomia às regiões de onde emanam importantes movimentos nacionalistas.

A crescente urbanização, alfabetização e mobilização política, as diferenças entre taxas de fertilidade e performance econômica de vários grupos étnicos, além do recrudescimento dos fluxos migratórios, são os fatores que desafiam e continuarão desafiando a estrutura interna dos Estados europeus, assim como suas fronteiras.

\section{Referências bibliográficas}

ALBUQUERQUE, E.S. As fronteiras na era da globalização e os novos rumos da geografia política. Revista Sociedade e Território. Natal, v.24, n.2, p. 209-222, 2012.

ANDERSON, B. Comunidades Imaginadas. São Paulo: Companhia das Letras, 2008.

ARON, R. Paz e guerra entre as nações. São Paulo: Editora da UNB, 2002.
CASTELLS, M. Fim de Milênio. São Paulo: Paz e Terra, 2012.

CASTRO, T. Teoria das Relações Internacionais. Brasília: Funag, 2012.

COSTA, W.M. Geografia Política e Geopolítica. 2a.ed., São Paulo: Edusp, 2008.

DIECKHOFF, A. A nação em todos os seus estados: as identidades nacionais em movimento. Lisboa, Piaget, 2000.

FOUCHER, M. Obsessão por fronteiras. São Paulo: Radical Livros, 2009.

GELLNER, E. Nações e Nacionalismo. Lisboa, Gradiva, 1993. GUIBERNAU, M. Nacionalismos: o estado nacional e o nacionalismo no século XX. Rio de Janeiro: Jorge Zahar Editor, 1997.

GUIBERNAU, M. La identidad de las naciones. Barcelona,:Ariel Libros, 2009.

HOBSBAWN, E. Nações e nacionalismo desde 1780: programa, mito e realidade. 6a.ed., Rio de Janeiro: Paz e Terra, 2013.

KEATING, M. La independencia de Escocia. Valencia: Universitat de Valencia, 2012.

KEDOURIE, E. Nacionalismo. 4a. ed, Madrid: Alianza editorial, 2015.

KYMLICKA, W. Estados, naciones y culturas. Córdoba: Almuzara, 2004.

LLOBERA, J. El dios dela modernidad: el desarrollo del nacionalismo en la Europa Occidental. Barcelona: Anagrama, 1996.

MARTIN, A. Fronteiras e Nações. São Paulo, Contexto, 1993.

MOODIE, A. Geografia e política. Rio de Janeiro: Zahar editores, 1965.

MORAES, A.C.R. (Org.). Ratzel. São Paulo: Ática, 1990.

MORGENTHAU, H. A política entre as nações. São Paulo: Editora UNB, 2003.

NYE, J. Compreender os conflitos internacionais: uma introdução à teoria e à história. 2a. ed., Lisboa: Gradiva, 2011.

OLIVEIRA, O. M. Velhos e novos regionalismos. Ijuí: Editoria Unijuí, 2009.

POUTIGNAT, P. \& STREIFF-FENART, J. Teorias da etnicidade. $2^{\text {a }}$.ed., São Paulo: Unesp, 2011.

PRADO, H.S. \& ESPÓSITO NETO, T. (org). Fronteiras e relações internacionais. Curitiba: Íthala, 2015.

RAFFESTIN, C. Por uma geografia do poder. São Paulo: Ática, 1993.

ROMÃO, F.V. Nacionalismos espanhóis: tensão e conflitualidade. Lisboa: Edições 70, 2014.

SCHERMA, M.A. As fronteiras das Relações Internacionais. Revista Monções. Dourados, v.1, n.1, 2012.

SHULZE, H. Estado e nação na história da Europa. Lisboa: Presença, 1997.

SMITH, A. Nacionalismo. Lisboa: Teorema, 2001.

SUZMAN, M. Ethnic nationalism and state power. New York: Palgrave, 1999.

\section{Rodolfo Pereira das Chagas}

Graduado em Geografia (bacharelado e licenciatura) na Universidade de São Paulo (USP), onde também concluiu mestrado e doutorado no programa de Geografia Humana. É docente dos cursos de Relações Internacionais e Comunicação Social no Centro Universitário Belas Artes de São Paulo (FEBASP), assim como ministra aulas nos cursos de Jornalismo e Geografia nas Faculdades Metropolitanas Unidas (FMU).

E-mail: rpchagas2@gmail.com 